\title{
58. The New Syntheses of Hydroxydroserone (The Pig- ment of Drosera Whittakeri), Phthiocol (The Pigment of Human Tubercle Bacillus), and Naphthopurpurin; and the Studies of the related Compounds.
}

\author{
By Chika KurodA. \\ Institute of Physical and Chemical Research, Tokyo. \\ (Comm. by R. MaJima, M.I.A., July 12, 1939.)
}

In the previous papers ${ }^{1) 23)}$ on the constitution of Shikonin, the several synthetical procedures of naphthazarin, naphthopurpurin, and their derivatives, and also their comparative properties were reported.

Subsequent experiments gave some interesting results, and suggested the syntheses of hydroxydroserone ${ }^{4)}$ ) $[c]$, the pigment of plant Drosera Whittakeri, and phthiocol ${ }^{6}$ [ $\left.f\right]$, the pigment of human Tubercle Bacillus. In this paper, these results may be summarized as follows.

1) It was confirmed that; [A] naphthazarin and any naphthoquinone* which contains no $\mathrm{OH}$ group in $\beta$-position of the quinone ring do not react with Na-bicarbonate, on the other hand; [B] naphthopurpurin, and any naphthoquinone* which contains the same $\mathrm{OH}$ group as mentioned above react, not only with Na-bicarbonate, but also with Na-salts of certain weak acids, such as acetate etc. These behaviours are applicable for the separation of the compounds of the above two systems [A] [B], because, when their solutions in water insoluble solvent are shaken with aq. solution of Na-salts as above mentioned, only the compounds of $[\mathrm{B}]$ system pass, into the aq-layer forming $\mathrm{Na}$ compounds. The $\mathrm{Na}$ compounds are generally crystallisable, and the quantitative determinations of $\mathrm{Na}$ as $\mathrm{Na}_{2} \mathrm{SO}_{4}$ proved to be mono- $\mathrm{Na}$ compounds; the position of $\mathrm{Na}$ is considered probably to be $\beta$ in the following examples, compounds formed :-

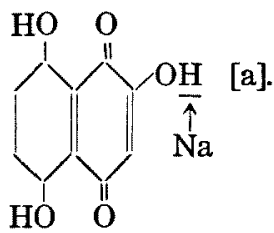

$\mathrm{C}_{10} \mathrm{H}_{5} \mathrm{O}_{5} \mathrm{Na}$. Brown red needles. Brown red needles.

Na. found 9.93

" calc. 10.04

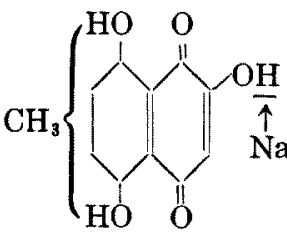

$\mathrm{C}_{11} \mathrm{H}_{7} \mathrm{O}_{5} \mathrm{Na}$

9.28

9.50 [b].<smiles>CC1=C(O)C(=O)C2=C(CCC1O)C(O)CCC2O</smiles>

Hydroxy droserone

$\mathrm{C}_{11} \mathrm{H}_{7} \mathrm{O}_{5} \mathrm{Na} 2 \mathrm{H}_{2} \mathrm{O}$. $\quad \mathrm{C}_{10} \mathrm{H}_{5} \mathrm{O}_{3} \mathrm{Na}$.

Dark-brown needles.

8.49

8.27

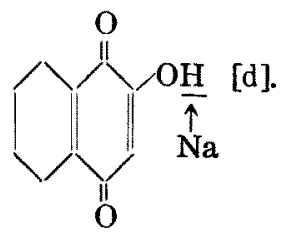

Red needles.

$11.71 \%$

$11.71 \%$

1) 2) Kuroda and Wada: Proc., 12 (1936), 239 ; 13 (1937), 163.

3) Kuroda and Wada: Sci. Pa. Inst. Ph. Ch. Res., (1938), 1741.

4) Winzor; J. Chem. Soc., 338 (1935).

5) Kuroda and Wada: Sci. Pa. Inst. Ph. Ch. Res. (1938), 1760.

6) Anderson and Newman: J. Biol. Chem., 103 (1933), 405.

*) Naphthoquinone (contains no acidic group such as $\mathrm{CO}_{2} \mathrm{H}, \mathrm{SO}_{3} \mathrm{H}$ ). 
2) A simple and improved method for synthesis of naphthopurpurin was found as follows: when a bluish solution of naphthazarin in $0.5 \%$ $\mathrm{NaOH}$ aq. was heated on the water bath for about one hour in contact with air using only a mechanical stirrer, naphthopurpurin was easily formed showing its reddish colour in the $\mathrm{NaOH}$ aq-sol. From the solution acidified with dil $\mathrm{HCl}$, almost pure naphthopurpurin was isolated by the aid of Na-bicarbonate and organic solvent as above mentioned: yield was nearly quantitative, leaving unchanged naphthazarin in the solvent: the above principle was applied to the other napho-quinones as follows:*

3) The $\mathrm{H}$ of $\mathrm{OH}$ group in $\beta$ position of the quinone ring was also noted to be active, namely that it is possible to be alkylated with alcohol and dry $\mathrm{HCl}$ gas: the experiments were carried out in the following compounds.<smiles>C[CH]OC1=CC(=O)C2=C(C(=O)CCCC2O)C(O)CC1</smiles>

Insoluble in Na-bicarbonate. Blue in $\mathrm{NaOH}_{\text {aq }}$.

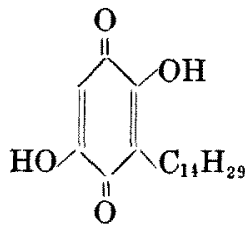

Rapanone.

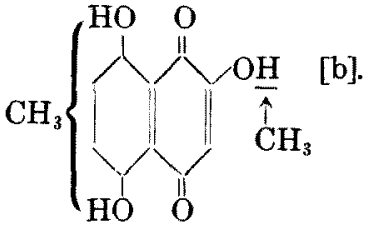

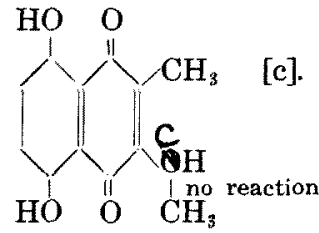

Soluble in Na-bicarbonate.

Red in $\mathrm{NaOH}_{\mathrm{aq}}$.<smiles>COC1=CC(=O)C(O)=C(C)C1=O</smiles>

[e].<smiles>CC1=C(O)C(=O)C2=C(CCCC2)C1=O</smiles>
[f].

With $\mathrm{CH}_{3} \mathrm{OH}$ and $\mathrm{HCl}$, methylation was successful in the case of [a] (the product mp. $178^{\circ}$ found $\mathrm{C}, 60.16 ; \mathrm{H}, 3.60 \%$ Calc. $\mathrm{C}, 60.00 ; \mathrm{H}, 3.64 \%$ ) and [b] whereas it was negative in the case of [c]. Furthermore, the treatment was applied to another quinone [d] Rapanone, which was studied by Dr. Kawamura" ${ }^{1)}$ who proposed the formula [d] for it, with which though anticipated Na-compound by the aid of Na-bicarbonate was obtained and methylation with $\mathrm{CH}_{3} \mathrm{OH}, \mathrm{HCl}$ in the above Na-compound was successful, yet only monomethyl ether (mp. $95^{\circ} \mathrm{CH}_{3} \mathrm{O}$, found $8.1 \%$ calc. $8.8 \%$ for which the present author proposed the formula [e]) was obtained, whereas di-methyl-ether was produced with diazo-methane.

In view of the above experimental results, it was thought that the alkyl group in $\beta$ position of quinone ring, the above mentioned, in acidic medium may hinder some reaction for $\mathrm{OH}$ group in its ortho position. It was moreover very interesting to be observed that by many chemists as well as by the present author, ${ }^{2)}$ in Thiele Winter's

*) See page 228 .

1) Rep. Jap. Sci. Ass., 377 (1937).

2) Kuroda and Wada: Sci. Pa. Inst. Ph. Ch. Res., 1740 (1938). 
method ${ }^{1)}$ which was carried out in acidic medium, namely $\left(\mathrm{CH}_{3} \mathrm{CO}\right)_{2} \mathrm{O}$ and $\mathrm{H}_{2} \mathrm{SO}_{4}$, alkyl group in $\beta$ position of quinone ring also hinders the introduction of OAc group into the quinone ring.

It was then anticipated that, in the case of an alkaline medium, on the contrary, some different influence may occur; with this idea therefore the author's method in which alkali was used for the preparation of naphathopurin as above mentioned, was applied to the compound maleic acid and tolu-hydro-quinone or, from citraconic acid and hydroquinone. The methyl naphthazarin $(0.5 \mathrm{~g})$ in $0.5 \% \mathrm{Na}-\mathrm{OH}$ aq. sol (150 c.c.) was treated in the similar manner in the case of naphthazarin itself : fortunately a very interesting and characteristic compound, hydroxy droserone [c] which was previously synthesized by the author ${ }^{2)}$ according to the literature ${ }^{3 \text { ) }}$ was produced. (in a good yield mp. $198^{\circ}$ alone or mixed with authentic specimen; its acetyl-der. mp. $152^{\circ}$ )

As the result of the above experiment, the synthesis of phthiocol was attempted. As the pigment is considered as a very important and interesting substance for a biological significance, several synthetic studies ${ }^{4)}$ (6) 6) 7) had been reported, however the processes were either rather complicated, or gave only poor yield.

In the present work the starting material<smiles>CC1CC(=O)C2CCCCC2C1=O</smiles>

(2g) which

had been obtained from $\beta$ methyl naphthalene and $\mathrm{CrO}_{3}$ was treated with $0.5 \% \mathrm{Na}-\mathrm{OH}$ aq. (600 c.c.) in a same way as previously mentioned. After acidifying with $\mathrm{HCl}$, the main product separated in reddish yellow crystals; the product dissolved in ether or benzene was treated with Na-bicarbonate, and the aq. layer was acidified; then crude phthiocol crystallized out. From aqueous mother liquor, some quantity of phthiocol was isolated by the aid of ether and Na-bicarbonate (yield $70 \%$ ). For analysis, the specimen was purified by sublimation and recrystallized from $50 \% \mathrm{CH}_{3} \mathrm{OH}$ (yellow needles mp. $173^{\circ}$ found $\mathrm{C}, 70.03$; $\mathrm{H}, 4.39 \%$. Calc. $\mathrm{C}, 70.22 ; \mathrm{H}, 4.26 \%$ ). Mono-acetyl derivative (white crystal mp. $106^{\circ}$, found $\mathrm{C}, 67.82 ; \mathrm{H}, 4.42 \%$ Calc. C, $67.82 ; \mathrm{H}, 4.34 \%$ ) was easily obtained when the pigment was treated with $\left(\mathrm{CH}_{3} \mathrm{CO}\right)_{2} \mathrm{O}$ and $\mathrm{H}_{2} \mathrm{SO}_{4}$. Triacetoymethy naphthalene (mp. $158^{\circ}$ in white crystal) was easily obtained when the pigment was treated with $\mathrm{Zn}$., $\left(\mathrm{CH}_{3} \mathrm{CO}\right)_{2} \mathrm{O}$ and Na-acetate.

1) Ann., 311 (1900), 345.

2) Kuroda and Wada: Sci. Pa. Inst. Ph. Ch. Res., (1938), 1741.

3) Winzer: J. Chem. Soc., 338 (1935).

4) Anderson and Newman: J. Biolo. Chem., 103 (1933), 405.

5) Madinavetia: An. Soc. espan fisic y qum., 31 (1933), 750.

6) Anderson: J. Biolo. Chem., 105 (1934), 279.

7) Hooker: J. Amer. Chem. Soc., 1168 (1936). 
Moreover the following compounds were synthesized and some interesting experiments are now in progress.<smiles>CO[C@H]1CC[C@@H](O)[C@@H](OC)[C@@H]1O</smiles>

Synthesized by 1 )

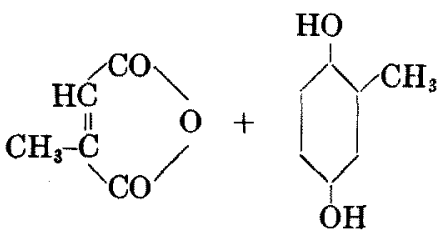<smiles>[Mg][AlH2]</smiles>

found $\mathrm{C}, 53.64 ; \mathrm{H}, 3.03 \%$ calc. C, $54.05 ; \mathrm{H}, 2.70 \%$<smiles>O=C1C(O)=C(O)C(=O)C(O)C2=C1C(O)CC(O)CC2</smiles>

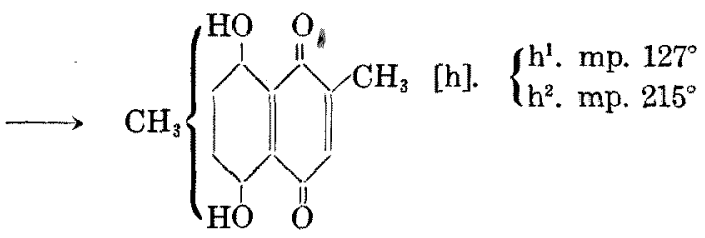

[h] found $\mathrm{C}, 66.29 ; \mathrm{H}, 4.81 \%$

$\left[\mathrm{h}^{2}\right]$. found $\mathrm{C}, 66.14 ; \mathrm{H}, 4.66 \%$ cal. $\mathrm{C}, 66.05 ; \mathrm{H}, 4.59 \%$

The author wishes to express thanks to Prof. R. Majima for his interest and encouragement in this work, to Miss Wada for her help in the preparation of the compounds $(\mathrm{g})$, (h) and to Mr. Watanabe for his kindful assistance in this work.

1) Baker: J. Chem. Soc., 1602 (1938). 